\title{
O uso do Blog como ferramenta pedagógica: um es- tudo de caso com professores participantes do Pro- jeto Um Computador por Aluno (UCA)
}

Title: Use of Blog as a pedagogical tool: a case study with teachers from One laptop per Student (UCA) Project

\author{
Renata Lopes Jaguaribe Pontes \\ Universidade Federal do Ceará - UFC \\ Instituto UFC Virtual \\ Av. Humberto Monte, s/n, bloco 901, 10 andar, \\ Cep:60440-554 \\ renata@virtual.ufc.br
}

\author{
José Aires de Castro Filho \\ Universidade Federal do Ceará - UFC \\ Instituto UFC Virtual \\ Av. Humberto Monte, s/n, bloco 901, 1o andar, \\ Cep:60440-554 \\ aires@ virtual.ufc.br
}

\begin{abstract}
Resumo Este artigo relata os resultados de uma investigação acerca da apropriação e utilização do Blog como ferramenta de ensino-aprendizagem por professores. A abordagem metodológica adotada foi de natureza qualitativa e a estratégia empregada foi o estudo de caso com três professoras do Ensino Fundamental de uma escola municipal de Fortaleza, Ceará, contemplada com o Projeto Um Computador por Aluno (UCA). Os dados foram coletados por meio das técnicas da observação participante e entrevista semi-estruturada. Os resultados indicam que iniciamente as professoras não conheciam as possibilidades educacionais do Blog, mas no decorrer da investigação obtiveram avanços no uso instrumental e pedagógico da ferramenta, assim como realizaram aulas experimentais nas quais estimularam os alunos a interagirem e colaborarem em rede. A formação realizada estimulou práticas pedagógicas inovadoras vinculadas a filosofia de colaboração e coautoria da Web 2.0. Em conclusão, para que as práticas sejam duradouras, há a necessidade de uma formação contínua e incentivo para o uso do Blog e outras ferramentas da Web 2.0.
\end{abstract}

Palavras-Chave: Blog, Web 2.0, Projeto UCA, formação de Professores.

\begin{abstract}
This paper describes the results of an investigation concerning the te appropriation and use of blog teaching and learning tool by teachers. The methodological approach adopted was qualitative with a case study strategy. Participantes were Three elementary teachers from a public school in Fortaleza, Ceará, awarded with the One Laptop per Student projetc (UCA). Data were collected using participant observation and semi-structured interviews. Results indicate that teachers were initially unaware of Blog educational possibilities. During the the investigation, they have advanced in the instrumental and pedagogical use and conducted experimental lessons which encouraged students to network interaction and collaboration. The program undertaken stimulated innovative pedagogical practices related to the Web 2.0 collaboration and coauthoring philosophy. In conclusion, to keep sustainable practice, continuous training and encouragement on the use of Blog and other Web 2.0 tools are needed.
\end{abstract}

Keywords: Blog, Web 2.0, One Laptop per student, Teachers professional development. 



\section{Introdução}

O surgimento e a rápida evolução das tecnologias de informação e comunicação (TIC) ocasionaram transformações e trouxeram possibilidades para todos os âmbitos da sociedade. No contexto educacional, essas tecnologias estão sendo cada vez mais utilizadas, criando oportunidades para mudanças nas relações de ensino e aprendizagem.

Alguns estudos [26; 32; 35] sobre laptop na educação apontam que o seu uso em sala de aula melhora o desempenho escolar. Um dos fatores, segundo os professores, é o fato de aumentar a gama de recursos com o acesso à Internet e a materiais digitais para incrementar a realização das atividades. Eles também verificam indícios de mudanças na organização da situação de aprendizagem, ao realizar mais trabalhos que visam promover a autoria e a co-autoria do aluno, favorecendo um clima apropriado para a aprendizagem colaborativa e a troca de experiências. Outro dado relevante é a observação que o laptop promove uma quebra de distâncias, o que revela o início de uma aprendizagem em rede que rompe com o modelo de educação tradicional, a qual se configura como individual e local.

Os professores também apontaram que o uso do laptop trouxe melhorias ao possibilitar aos alunos debaterem, questionarem e realizarem pesquisas de forma autônoma, assumindo uma postura ativa por ter ao seu alcance a oportunidade de esclarecer os próprios questionamentos. Os ganhos relatados foram principalmente, relativos à escrita dos alunos, pois, com a Internet, eles tiram dúvidas sobre a ortografia de uma palavra ou seu significado, além de contar com exemplos que despertam a criatividade.

Ainda de acordo com os estudos citados, tanto os docentes quanto os alunos mencionaram que o uso do laptop lhes dava a oportunidade de aprender e conhecer aspectos jamais imaginados por eles, tais como o sistema operacional, jogos de raciocínio e lógica e desenvolver desenhos gráficos elaborados com um programa específico.

Para atender estas novas possibilidades, no entanto, o professor precisa possuir domínio instrumental e pedagógico no uso das TIC. Nas últimas três décadas, esforços vêm sendo realizados para atender essa necessidade por meio de várias iniciativas de formação de professores. Essas ações abrangem a oferta de cursos de pósgraduação stricto (mestrados e doutorados) e lato sensu (especializações) relacionados com informática educativa, passando por cursos e disciplinas ofertados por Instituições de Ensino Superior, até iniciativas nacionais do Governo Federal para a implantação da informática educativa com os Projetos Educação por Computador -
EDUCOM, Formar, Formar I e Formar II, o Programa Nacional de Informática Educativa - PRONINFE e o Programa Nacional de Informática na Educação PROINFO [1].

Além da capacitação docente, também devem ser empregadas ferramentas que possibilitem uma aprendizagem em rede e estimulem a formação de conexões entre professores e alunos com o conhecimento. Harasim et al [19] afirmam que "as redes permitem que a educação se torne interinstitucional, expandindo imensamente o acesso de alunos e professores a recursos de informação e conhecimento especializado em todo o mundo".

Dentre os recursos oferecidos pelo computador e disponíveis por meio do acesso à Internet, temos o Blog. Essa ferramenta está associada à $W e b$ 2.0, tida como uma evolução da estrutura da Internet, que visa uma ampla participação dos usuários da rede por meio de canais colaborativos, nos quais eles podem atuar como emissores e produtores de conteúdo, estimulando a autoria, a interatividade e a socialização.

Uma característica da Web 2.0, ressaltada por Fonseca e Lindemann [10], é a capacidade de superação do modelo tradicional de transmissão de informação "emissor-meiomensagem-receptor". Ferramentas com o Blog, Wiki, Youtube e Twitter propiciam que o usuário abandone a sua posição de receptor passivo, tornando-se também produtor de conteúdo, o que descentraliza a emissão e permite que mais vozes possam se manifestar na Internet.

Este artigo relata os resultados de uma investigação acerca da apropriação e utilização do Blog como ferramenta de ensino-aprendizagem por três professoras da educação básica de uma escola piloto contemplada com o Projeto Um Computador por Aluno (UCA). O artigo está estruturado da seguinte forma: primeiramente, apresentamos um panorama geral sobre o Projeto UCA, seguido de uma discussão sobre o uso de Blog na educação; apresentação da metodologia adotada para coleta e geração de dados, os resultados provindos da análise de dados e, por último, as considerações finais.

\section{O Projeto Um Computador por Aluno (UCA)}

Em janeiro de 2005, durante o Fórum Econômico Mundial de Davos, na Suíça, o pesquisador Nicholas Negroponte apresentou, ao então presidente Luiz Inácio Lula da Silva, a idéia da organização não-governamental One Laptop per Child (OLPC) de distribuir computadores de US\$ 100 para cada criança de escolas públicas de países em desenvolvimento. O objetivo principal da OLPC era o de promover a inclusão digital [4].

Os Ministérios da Educação e da Ciência e Tecnologia avaliaram a proposta de Negroponte, quanto aos as- 
pectos técnicos e pedagógicos, modificando a ideia original da OLPC ao enfatizar que o projeto brasileiro teria como objetivo principal a utilização pedagógica do laptop.

Em junho de 2006, o Projeto Um Computador por Aluno (UCA) foi lançado oficialmente. Em 2007, foi iniciada a sua fase pré-piloto com experimentos em cinco escolas públicas de ensino fundamental, distribuídas nos estados brasileiros de São Paulo, Rio Grande do Sul, Tocantins, Rio de Janeiro e Distrito Federal.

Em março desse mesmo ano, o Grupo de Trabalho do Projeto UCA (GTUCA) redigiu um documento para sistematizar os pressupostos teóricos do UCA. O documento oferecia um guia de orientações à comunidade escolar brasileira para as ações pedagógicas com o laptop e, principalmente, dava uma referência para a estruturação do modelo de formação docente das escolas durante a fase piloto [32].

Dentre os princípios pedagógicos do Projeto, descritos no documento, destacam- se: a exploração pedagógica da mobilidade do laptop; a formação de comunidades de aprendizagem; a interação entre as pessoas e a construção coletiva do conhecimento; a promoção de letramentos de leitura, escrita, digital, visual e sonora; a integração do laptop ao currículo; a apropriação dos recursos das TIC e a constituição de redes de construção coletivas, nas quais professores e alunos exploram diferentes alternativas para um mesmo problema [4].

O Projeto UCA está atrelado a uma concepção de aprendizagem em rede que possibilita o desenvolvimento de conteúdos por múltiplas conexões entre alunos e professores da mesma e de diferentes localidades visando a produção de conteúdo, troca de idéias, discussões, entre outras possibilidades [32]. As ferramentas da Web 2.0 são meios adequados para o desenvolvimento da aprendizagem em rede, pois representam uma nova forma de utilizar a Internet, na qual a informação é empregada e avaliada por outras pessoas que interagem e colaboram com o conteúdo e seus criadores para criar e compartilhar conhecimento [21].

Essas práticas são opostas à linearidade da educação tradicional centrada no ensino e nas transferências do conhecimento encontradas atualmente nas escolas. Para Freire [11] "ensinar não é transferir conhecimento, mas criar as possibilidades para a sua produção ou sua construção".

Em 2010, foi iniciada a segunda fase do Projeto UCA, denominada de fase piloto, na qual se situa esta pesquisa. Foram selecionadas 300 escolas públicas, entre elas nove no estado do Ceará. Este trabalho foi realizado em uma escola municipal de Fortaleza, contemplada com o UCA. O conteúdo da formação docente do Projeto UCA engloba um módulo que trata exclusivamente sobre as características e recursos da $\mathrm{Web} 2.0$, dentre eles o Blog, que será discutido na próxima seção.

\section{O Blog na Educação}

A evolução da Internet e de suas ferramentas possibilitou uma nova fase para o internauta que passou a ser autor e produtor de suas informações. Essa nova fase ficou conhecida como Web 2.0. Um dos maiores exemplos dessa evolução são os Weblogs.

Surgidos no final dos anos 90, os Weblogs, mais comumente conhecido como Blog, surgiram como um diário virtual para o compartilhamento de pensamentos, relatos e reflexões pessoais. Os primeiros Weblogs exigiam um conhecimento técnico de programação e linguagem HTML para serem criados. Em 1999, foram criados os primeiros aplicativos e serviços de Weblogs, como o Blogger $^{1}$. Estes sistemas gratuitos e de baixo custo facilitaram a disseminação da prática do Weblog, e permitiram que qualquer pessoa pudesse ser um blogueiro (como é chamado o autor de um Blog).

As páginas de um Blog disponibilizam espaços para comentários, permitindo ao leitor dialogar com o autor, concordando, discordando ou acrescentando outros elementos, como links para outros Blog que tratem da mesma temática. Esse recurso incentiva a interação entre os usuários, diferenciando o ato de blogar do ato de navegar. Assim, o internauta fica livre para traçar um percurso de leitura próprio que não se baseia somente na escolha dos links disponibilizados pelo autor. Porém, para que essa atuação realmente aconteça, é necessário que o blogar seja uma ação coletiva e construída pelos blogueiros e leitores, que acabam atuando também como autores [30].

Por proporcionar e incentivar a interação e a colaboração, os Blogs têm sido usados para diversos fins: pessoal, corporativo ou de entretenimento.

Atualmente, o Blog também ocupa um lugar de destaque no contexto educacional, comprovado pelos inúmeros Blogs com fins pedagógicos. Barbosa e Granado [2] corroboram com essa afirmação dizendo que "se há alguma área onde os weblog podem ser utilizados como ferramenta de comunicação e de troca de experiências com excelentes resultados, essa área é sem dúvida, a da educação". Essa troca de experiências tem potencial para fomentar a aprendizagem em um contexto de colaboração, conforme comprova a pesquisa realizada por Carmo e Pontes [5]. Os autores destacam que o Blog representa um rico espaço de interação entre os estudantes.

Silva e Albuquerque [33] elencam cinco categorias de Blogs educacionais: Blog de professores, utilizado para publicar orientações, textos, vídeos, imagens, animações, referências bibliográficas ou links; Blog de alunos, que funcionam como portfólios reunindo suas produções e que são utilizados pelos professores como instrumentos de avaliação; Blog de instituições educativas, voltados à

\footnotetext{
1 www.Blogger.com
} 
divulgação do trabalho desenvolvido; Blog de projetos educativos, destinados à produção e socialização de conhecimentos sobre temas específicos e Blog de grupos de pesquisa, reunindo pessoas de comunidades científicas diversas para interlocução, articulação de suas pesquisas, divulgação, análise de resultados e avaliação de textos.

O Blog também possui outras vantagens educativas significativas para o incentivo à interação e a colaboração. Oliveira [29] cita a possibilidade da ferramenta estimular o papel do professor como mediador na produção de conhecimento, já que ele tem um papel ativo de instigar as discussões por meio de comentários, potencializando a interação entre a classe; incentivar a escrita colaborativa, a autoria, o pensamento crítico e a capacidade argumentativa; estimular o aprendizado extra-classe de forma lúdica; desenvolver a habilidade de pesquisar e selecionar informações. Pesquisas como a de Kim [22] e Hemmi et al. [20] destacam o potencial do Blog para o senso de responsabilidade relacionado à qualidade das informações escritas no momento que os alunos se tornam autores dos conteúdos postados.

O Blog vem despertando, cada vez mais, a atenção de pesquisadores que buscam em suas características, potencialidades para a educação. Gomes [13], por exemplo, desenvolveu um estudo para sistematizar um conjunto de possíveis vertentes de exploração do Blog no contexto escolar, usando uma abordagem que explora as possibilidades do Blog como recurso e como estratégia pedagógica. Segundo a autora, enquanto recurso pedagógico o Blog pode ser: um espaço de acesso a informação especializada ou de disponibilização de informação por parte do professor. Já, enquanto estratégia pedagógica, o Blog pode assumir a forma de um portfólio digital, um espaço de intercâmbio e colaboração, um espaço de debate e integração.

Gutierrez [18] e Richardson [31] listam os seguintes motivos para um professor criar um Blog: potencializa a interação entre os alunos; desenvolve o papel do professor como mediador na produção do conhecimento; incentiva a autoria, o pensamento crítico e a capacidade argumentativa dos alunos; explora o conteúdo e o hipertexto; estimula o aprendizado extra-classe de forma lúdica; impulsiona o exercício do diálogo entre alunos e professores. Marinho et al [25] acrescentam um novo motivo: criar um Blog é uma boa estratégia para um professor inserir-se de forma ativa na rede, iniciando sua cultura de uso de recursos da Web 2.0 e assim sentir-se mais confortável para aplicá-lo juntos aos alunos.

Ainda há poucos estudos empíricos acerca do uso do Blog na escola, especialmente no que se refere ao seu uso por professores. O presente estudo investigou de que forma os professores de uma escola participante do Projeto UCA se apropriaram do Blog, como ferramenta pedagógica. Na próxima seção detalhamos a metodologia utilizada no estudo.

\section{Metodologia}

O estudo foi desenvolvido durante os meses de fevereiro e março de 2011 e julho de 2013 com três professoras polivalentes do ensino fundamental: duas professoras do $4^{\circ}$ ano e uma professora do $5^{\circ}$ ano, as quais denominamos, respectivamente, de professoras $\mathrm{A}, \mathrm{B}$ e $\mathrm{C}$, de uma escola municipal de Fortaleza contemplada com o Projeto Um Computador por Aluno (UCA). A pesquisa teve como objetivo investigar os avanços e dificuldades destas professoras na apropriação e uso pedagógico do Blog em suas práticas pedagógicas.

A abordagem metodológica adotada foi a pesquisa qualitativa. De acordo com Flick [9] e Bogdan e Biklen [3], esse tipo de pesquisa propõe compreender o processo pelo qual os sujeitos realizam alguma ação.

Entre as principais características da pesquisa qualitativa destaca-se o maior interesse dos investigadores pelo processo do que pelos resultados ou produtos [3]. A pesquisa qualitativa explicita a importância do acompanhamento do processo para a verificação de como o problema investigado é manifestado em atividades, procedimentos e interações cotidianas [12]. O interesse da presente pesquisa foi compreender, descrever e analisar os avanços e dificuldades das professores no entendimento e no uso de Blog.

A estratégia adotada foi o estudo de caso. Ludke e André [24] afirmam que a concepção do estudo de caso não advém de uma visão predeterminada da realidade, mas busca apreender os aspectos ricos e imprevistos de uma determinada situação. Esses autores elencam as características principais de um estudo de caso: visam à descoberta; enfatizam a interpretação em contexto; buscam retratar a realidade de forma completa e profunda; usam uma variedade de fontes de informação; revelam experiência vicária e permitem generalizações naturalísticas; procuram representar os diferentes pontos de vista presentes numa situação social; e utilizam uma linguagem e uma forma mais acessível do que os outros relatórios de pesquisa.

Para Bogdan e Biklen [3], o estudo de caso pode ser concebido como um funil em que o início do estudo é sempre a parte mais larga. Mas que, quando aprofundado, envolve um ou poucos sujeitos. Mesmo abrangendo poucos sujeitos, esse tipo de pesquisa pode revelar dados universais, como explica Chizzotti [6]: "o estudo de caso não visa generalizações, mas um caso pode revelar realidades universais, porque, guardadas as peculiaridades, nenhum caso é isolado, independente das relações sociais que acontecem."

A seleção dos sujeitos foi realizada pela disponibilidade e interesse apresentados por eles durante os contatos 
prévios antes da Oficina e, principalmente, durante a realização da Oficina. Outro critério utilizado foi a seleção de professores que tivessem um mínino de conhecimento sobre o uso de um computador, por exemplo, que conseguissem manusear o mouse, digitar no teclado, saber usar os navegadores da Internet e entender alguns comandos e símbolos padrões, como o fechar (representado pelo " $x$ "), minimizar e maximizar. Desta forma, no curto espaço de tempo que dispusemos, podíamos desenvolver mais ações voltadas para o uso instrumental e pedagógico do Blog pelos docentes investigados.

A pesquisa foi composta por cinco momentos distintos: 1) Identificação dos conhecimentos prévios das professoras acerca do Blog, tendo em vista conheceremos se já haviam utilizado a ferramenta e se fazia parte de suas práticas pedagógicas.

2) Realização de uma oficina sobre criação e utilização pedagógica de Blogs. A Ofícina aconteceu no laboratório de informática da escola durante dois dias, com carga horária total de 6 horas, e aliou tanto aspectos teóricos como: a apresentação de características do Blog (interação, produção, colaboração e autoria) e algumas possibilidades para seu uso pedagógico, quanto aspectos práticos como o acesso ao site Blogger e a criação de um $B l o g$ pedagógico por cada uma das professoras.

3) Acompanhamento pedagógico das três professoras no planejamentos da aulas (elaboração dos objetivos da aula e organização do Blog para alcançá-los, aliados a momentos de apropriação tecnológica). Esses encontros com as professoras selecionadas para acompanhamento pedagógico surgiram após a oficina e envolveram uma maior apropriação do acesso e funcionalidades do Blog, o que não foi possível durante a oficina pela falta de tempo disponibilizado.

Os acompanhamentos pedagógicos foram intercalados com o planejamento de aulas usando esse recurso. Esses planejamentos surgiram a partir de sugestões nossas e de ideias das professoras, sujeitos da pesquisa, baseados em conteúdos do livro didático das séries trabalhadas. Durante essa etapa, observamos o uso do Blog pelas professoras, analisando se e como o conhecimento acerca desse recurso foi modificado.

4) Realização de aulas experimentais com o uso do Blog por meio do laptop educacional. Nessa etapa observamos a atuação das professoras em aulas experimentais, analisando como utilizam a ferramenta Blog e como se comportam em relação aos alunos.

5) Follow-up do uso e do não-uso do Blog pelas professoras. Nessa etapa buscamos acompanhar o uso do Blog e o avanço das professoras investigadas na apropriação dessa e de outras ferramentas dois anos após a realização da formação.

Os dados foram coletados por meio de observações realizadas durante a Oficina, acompanhamentos pedagó- gicos e aulas, com o intuito de observar as mudanças na compreensão do uso pedagógico do Blog pelas docentes; e entrevistas semi-estruturadas feitas com as professoras antes da Oficina e ao final das aulas acerca do uso desta ferramenta em sua prática pedagógica.

Os instrumentos de coleta de dados utilizados nesse trabalho - entrevistas e observações (diário de campo e gravação de áudio) - são descritivos. Esse tipo de material é rico em detalhes e pode ser usado para subsidiar afirmações ou esclarecer pontos de vista [24].

A observação é uma técnica de coleta de dados característica da abordagem qualitativa que atualmente ocupa uma posição de destaque na pesquisa educacional. Ludke e André [24] explicam a relevância da observação afirmando que ela "possibilita um contato pessoal e estreito do pesquisador com o fenômeno pesquisado. [...]. Além disso, as técnicas de observação são extremamente úteis para 'descobrir' aspectos novos de um problema."

Juntamente com a observação, a entrevista representa um dos instrumentos principais de coleta de dados dentro da perspectiva da pesquisa qualitativa. A grande vantagem da entrevista em relação a outras técnicas é que ela possibilita angariar de forma imediata e corrente a informação desejada [24]. A entrevista também proporciona uma maior veracidade aos fatos pesquisados, já que, ela nos oportuniza "recolher dados descritivos na linguagem do próprio sujeito, permitindo ao investigador desenvolver intuitivamente uma idéia sobre a maneira como os sujeitos interpretam aspectos do mundo" [3].

Passadas as etapas de investigação, realizamos a análise dos dados, constituindo um "processo de busca e de organização sistêmica de transcrição de entrevistas, de notas de campos e de outros materiais que foram sendo acumulados, com os objetivos de aumentar a sua própria compreensão" [3]. Em seguida, fizemos uma triangulação desses dados, ou seja, cruzamos os mesmos para uma maior validação dos dados coletados. Na próxima seção detalhamos os resultados que emergiram da análise.

\section{Resultados}

Na presente seção, apresentamos os resultados alcançados durante o processo de investigação da pesquisa. $\mathrm{O}$ caminho percorrido em busca dos objetivos especificados compreende a identificação dos conhecimentos e usos prévios do Blog pelas professoras investigadas; as mudanças em seus usos instrumentais e pedagógicos surgidos durante a Oficina; os momentos de acompanhamento pedagógico; a realização de aulas experimentais, e o acompanhamento do uso ou não-uso do Blog e o avanço das professoras investigadas na apropriação dessa e de outras ferramentas. 


\subsection{Identificando os conhecimentos e usos prévios}

Buscando identificar os conhecimentos prévios das professoras acerca do Blog, indagamos se já haviam utilizado a ferramenta, se fazia parte de sua prática pedagógica, se já haviam criado algum Blog. As professoras A e B relataram que consultavam e liam Blog educativos, mas que nunca os haviam utilizado em sala de aula, enquanto que a professora $\mathrm{C}$ disse que acessa $B \log$ para retirar sugestões de atividades que possam ser usadas nas aulas:

Sempre que eu faço busca de atividade, arte principalmente, eles são maiores e eu não posso ficar dando figurinha para eles pintarem, então hoje mesmo a gente trabalhou Romero Brito, eu já tirei de um Blog. Aula passada a gente trabalhou sobre bonsai, também tudo eu tirei de um Blog. Tanto tiro a parte teórica do assunto como eu tiro sugestões de atividades. (Professora C, Entrevista, 23/11/2010).

As três professoras disseram nunca terem criado um $B \log$ pelos seguintes motivos: a professora B considerava que criar um Blog é uma tarefa difícil e ainda distante de sua realidade e que por isso somente os acessava: "criar não, eu só faço olhar, às vezes a gente abre aquele site e tem a indicação daquele Blog, aí eu dou uma olhada" (Entrevista, 02/02/2011). Concordando com o pensamento da professora $\mathrm{B}$, a professora $\mathrm{A}$ afirmou que nunca havia pensando em criar um Blog. Já a professora $\mathrm{C}$ revelou ainda não ter criado um por ter receio dele não ficar igual aos que conhece: "nunca criei, mas para criar eu acho que é fácil, mas eu queria o meu assim lindo e maravilhoso igual aqueles outros que o cursor não é o cursor, sabe, eu acho tão lindo" (Entrevista, 23/11/2010).

Nas falas das professoras percebemos que elas conhecem o que é um Blog, mas que ainda o utilizam seguindo as características da Web 1.0, ou seja, como consumidoras de informações especializadas sobre educação, desconhecendo as possibilidades de seu uso como "estratégia pedagógica" [14]. Além da falta de conhecimento acerca das potencialidades pedagógicas, percebemos a ausência de conhecimentos técnicos para utilizar a ferramenta.

Os depoimentos expostos acima foram mais bem compreendidos durante a Oficina, quando observamos que as três professoras não somente apresentam variados níveis de apropriação tecnológica, como diferentes domínios instrumentais do computador, que refletem na insegurança em usar uma tecnologia como o Blog, considerada por elas como mais sofisticada.

\subsection{Mudanças na percepção docente acerca do uso instrumental e pedagógico do Blog}

$\mathrm{Na}$ Oficina, cada professora criou um Blog com facilidade, ao seguir os passos descritos no próprio Blogger e contando com a nossa orientação (ver figuras 1 e 2). Após criarem um Blog partiram para a elaboração de sua primeira postagem. Neste momento, as professoras A e B se restringiram a escrever o texto e a tentar inserir uma imagem, tarefa que a professora B achou "a mais difícil" durante a formação, enquanto que a professora $\mathrm{C}$ foi além ao realizar duas postagens e ao mudar o design do plano de fundo, a fonte e as cores do texto da postagem.

As três professoras comentaram ter gostado de usar a ferramenta e ficaram satisfeitas por terem conseguido criar um Blog, fato que desmitificou para as professoras A e B que era difícil criá-lo. "Adorei! Foi superfácil. Consegui criar meu Blog!" (Diário de campo, 05/02/2011), disse a professora B, enquanto a professora A achou que foi "fácil" e "interessante" criar um Blog (Diário de campo, 05/02/2011).

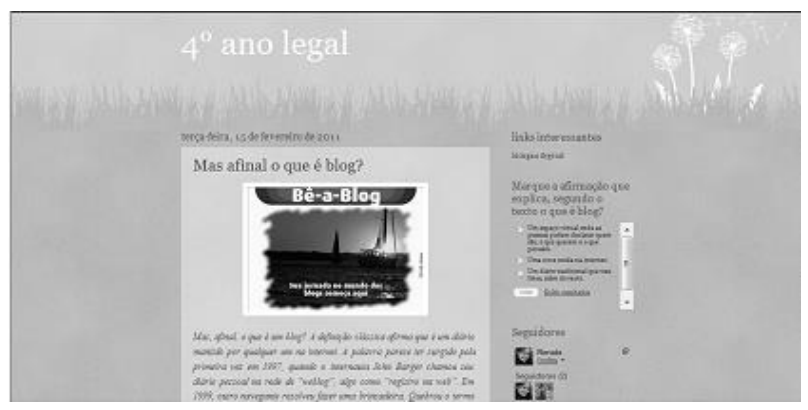

Figura 1: Blog criado pela professora A.

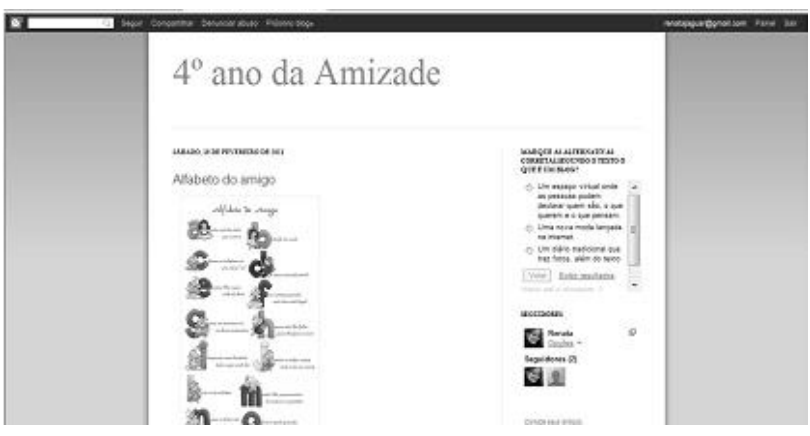

Figura 2: Blog criado pela professora B.

Ao contrário das outras duas professoras, a professora C não demonstrava preocupação em criar um Blog e sim em conseguir modificá-lo. Ela tinha receio de não conseguir deixá-lo com queria: com as cores e os efeitos que havia visto em outros Blog educativos. Perseguindo esse objetivo, ao final do primeiro dia da formação, ela já 
estava perguntando acerca de funções mais específicas e sofisticadas da ferramenta, tais como: mudar o endereço do Blog, pois, queria colocar o mesmo do título interno; colocar sua foto e descrever seu perfil; e de que forma poderia seguir o Blog das outras professoras. A partir de suas dúvidas, mostramos os locais no Blog onde poderia realizar tais ações.

No segundo dia da oficina, visualizamos que o Blog dela já estava totalmente diferente do que foi criado inicialmente. Ela comentou que quando estava praticando em casa havia modificado o design do plano de fundo (ver figuras 3 e 4). Em entrevista após a oficina, ela comentou: "O Blog era uma coisa que eu conhecia, mas eu nunca imaginei assim, eu achava que criar Blog era fácil, eu achava que difícil era colocar todo o resto, layout, mas acho que tudo é uma questão da gente começar e ter vontade de continuar" (Entrevista, 11/02/2011).

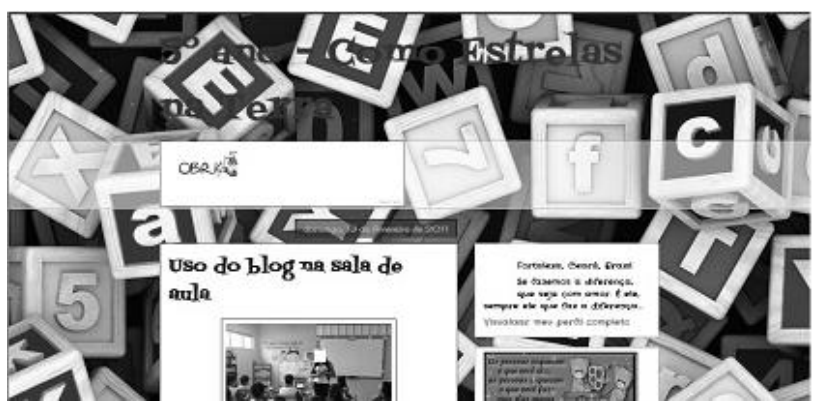

Figura 3: $B \log$ criado pela professora C.

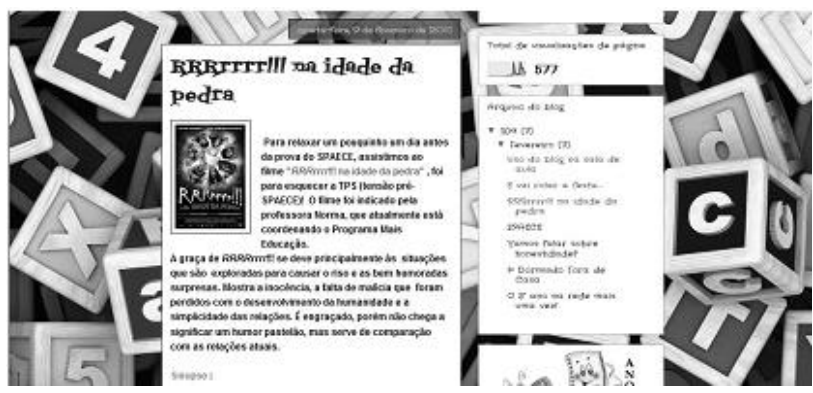

Figura 4: Postagem com imagem e links no Blog da Professora C.

Durante a oficina, também falamos sobre os cinco tipos de Blog educacionais elencados por Silva e Albuquerque [33] e acessamos exemplos dos mesmos na Internet. Aproveitamos esse momento para comentar sobre algumas sugestões de atividades pedagógicas que utilizam a ferramenta como: espaço para reflexões e perguntas, onde os os alunos possam se posicionar sobre as postagens ou comentários; espaço para a realização de histórias coletivas (contos, peças, entre outros) onde a turma inteira se envolve com o desenvolvimento; local para registrar e comentar atividades realizadas durante as aulas com a inserção de fotos e áudios (entrevistas, relatos), produzidos pela câmera do próprio laptop educacional do Projeto UCA.
Além disso, apresentamos algumas formas de interação permitidas pela ferramenta Blog, como: a possibilidade de adicionar alguém como autor ou administrador para realizar postagens; a função dos comentários existente em cada postagem; e a possibilidade de elaborar uma postagem multimídia com vídeo, imagens e hiperlinks.

No momento seguinte, propomos às professoras a seguinte reflexão: "Como eu, professor, poderia incorporar essa ferramenta em minha prática pedagógica?" e pedimos que cada uma elaborasse uma proposta de uso pedagógico do Blog.

A professora A teve a ideia de criar um Blog que incentivasse a leitura dos alunos que, segundo ela, é uma das maiores deficiências dos alunos do quarto ano. Ela postou um texto do Mário Quintana e disse que iria postar outros posteriormente para que os alunos lessem. "A minha ideia é assim incentivar a leitura, criar um [Blog] que eles possam sentir vontade de ler, o nome é 'Para ler e gostar é só começar', eu estou vendo aqui, estou tentando concretizar essa idéia, né" (Professora A, Informação verbal gravada e transcrita no Diário de campo em 05/02/2011). Enquanto que a professora B pensa em utilizar o Blog para expor idéias de trabalhos manuais que faz individualmente e atividades realizadas em sala de aula com os alunos.

Eu quero fazer um Blog voltado para desenho e pintura, porque eu gosto muito de trabalhos manuais, eu gosto de trabalhar com sucata, eu até fiz uns fantoches que eu trouxe, então eu quero dar essas ideias, sabe, eu quero botar isso no meu Blog, e também trabalhos realizados com os meninos, com os alunos, em sala de aula, e como é importante a gente valorizar o trabalho deles, como eles se sentem importantes, então é isso que eu vou fazer no meu Blog (Professora B, Informação verbal gravada e transcrita no diário de campo em 05/02/2011).

Já a professora C elaborou um Blog voltado para as suas turmas atuais e futuras de quinto ano, contendo assuntos que estavam sendo abordados em sala de aula e eventos que haviam participado na escola, como ela própria explica:

Eu estou pensando em fazer o Blog da $5^{\circ}$ série, mesmo que essa quinta sala tem a outra quinta e continuar o Blog, a gente pensa em colocar os meninos também como autores colaboradores, que eles vão poder postar, então assim, para os meninos colaborarem colocando postagens e não só os comentários, né, a gente fazer as atividades e servir como editor de texto, né, para eles escreverem, que já são maiores se interessam, e na hora que eles forem vendo postagens com as fotos deles, eles vão se achar bem valorizados, podemos fazer texto coletivo, $e$ eu já andei olhando tem muito [Blog] que vocêfaz testes, teste de honestidade, então dá pra você usar como atividade. Eu tô colocando de acordo com o planejamento, o planejamento deste mês, a honestidade já fiz, já coloquei aquela lenda da flor, aquela lenda japonesa, coloquei 
com a foto da rosa, para quando verem o Blog eles possam remeter ao que a gente está trabalhando na sala, para que eles falem sobre o tema, ai depois que ele lerem a história, tem uma reflexão final. (Professora C - Informação verbal gravada e transcrita no diário de campo em 05/02/2011).

Observamos que as três professoras propuseram distintos usos pedagógicos para os seus Blogs. A professora A enfatizou que o seu objetivo principal era o de estimular a leitura, porém, demonstrou que ainda não sabia exatamente como propor isto utilizando os recursos do Blog.

A professora B mostrou mais clareza ao comentar sua proposta, entretanto, revelou possuir um olhar ainda tradicional e limitado do uso pedagógico do Blog, ao colocar-se como a única autora de conteúdo do mesmo.

A professora $\mathrm{C}$ propôs um uso que reflete os conceitos de interação, autoria e colaboração pregados pela $\mathrm{Web}$ 2.0 , vislumbrando que tanto ela quanto os alunos serão produtores do conteúdo exposto no Blog.

Consideramos que, por ainda não conseguiram vislumbrar e se apropriar da maioria das funções que a ferramenta oferece, as professoras A e B se restringiram a usar o Blog como recurso pedagógico, quando é destinado a ser um espaço de acesso a informação especializada ou um espaço de disponibilização de informação por parte do professor [13]. Neste momento, constatamos que mesmo reconhecendo o Blog como um local onde se pode produzir conteúdo, as professoras não conseguiram idealizar os alunos também como participantes e possíveis autores, colocando-os na posição de receptores e consumidores, ou seja, utilizando uma ferramenta da $\mathrm{Web} 2.0$ como qualquer outro recurso da $W e b 1.0$.

Já a professora $\mathrm{C}$, por ter conseguido se apropriar da ferramenta, conseguiu visualizar outras possibilidades pedagógicas juntos aos alunos, por meio da utilização de funções disponíveis no $B l o g$, como comentários e enquetes.

Avaliando a oficina, observamos que ela possibilitou duas mudanças principais: 1) A ação de criar um Blog, escolhendo o layout e o que seria postado possibilitou que as professoras atuassem como produtoras de conteúdo e se vissem na posição de autores, já que, quando se trata de ferramentas e softwares educativos "(...) é raro os professores participarem, por exemplo, do processo de criação" [17]; 2) A desmistificação da criação e a utilização do Blog pelas professoras, ao vivenciarem a facilidade do uso desta ferramenta, que não exige do usuário conhecimento de linguagens de programação ou um sofisticado domínio instrumental para realizar as suas atividades principais, no caso, a elaboração de postagens. A oficina serviu como um momento inicial de apropriação tecnológica para o uso do Blog, possibilitando que as professoras identificassem algumas de suas funções bási- cas.

Durante a oficina também queríamos incentivar e enfatizar junto as professoras a importância de se apropriar do laptop educacional. Desta forma, antes da sua realização, solicitamos que elas trouxessem seus laptops, pois era preferível praticar na própria máquina, já que esse é o computador os quais os alunos têm acesso.

Ao saber da nossa proposta, a professora do laboratório de informática comentou que era preferível usar os computadores do laboratório, argumentando que seria mais fácil para elas se apropriarem do Blog em um computador com um processador mais veloz e com uma tela maior que possibilitasse uma visão melhor das funções da ferramenta.

As docentes investigadas alegaram esses mesmos motivos e preferiram usar os computadores do laboratório. A resistência ao uso do laptop durante a oficina nos fez constatar que apesar das várias facilidades trazidas pela máquina, como: a mobilidade, acesso à Internet e promoção de letramentos multimidiáticos, algumas limitações tanto de software (velocidade) quanto de hardware (tamanho da tela) desestimulavam o seu uso em momentos de apropriação tecnológica.

Apesar da resistência para utilizar a máquina, constatamos que esse obstáculo somente foi imposto pelas professoras durante a Oficina, como veremos adiante, mas que a mesma dificuldade não surgiu quando o laptop foi usado durante a aula com os alunos.

No entanto, como comenta Cysneiros [7], uma coisa é ensinar uma pessoa a usar o computador, outra é ensinála a usá-lo em contextos educacionais com os objetivos de ensinar e aprender. Desta forma, constatamos não somente a necessidade de uma continuação da apropriação tecnológica do Blog, mas também de um acompanhamento pedagógico que possibilite a realização de planejamentos de aulas que o utilizem como um meio que auxilie o processo de ensino-aprendizagem.

Após a Oficina, agendamos com as três professoras encontros para continuarmos a apropriação tecnológica do Blog. Nestes momentos as professoras A e B publicaram postagens com textos e imagens que seriam comentadas pelos alunos em sala, além de inserirem uma lista de links, outra funcionalidade do Blog.

Durante o acompanhamento pedagógico que teve duração de cerca de um mês desde a oficina até a realização das aulas, observamos que estas duas professoras avançaram no domínio instrumental da ferramenta ao conseguirem realizar por conta própria as seguintes ações: acessar o Blog, realizar uma postagem com texto e imagem, escrever comentários sobre estas postagens e inserir uma lista de links de sites educativos.

Enquanto que foi necessário realizar este trabalho de apropriação com as professoras A e B, tivemos poucos encontros com a professora $\mathrm{C}$ para que pudéssemos apre- 
sentar algumas funções, como a inserção de lista de links e enquete, no entanto, ela descobriu novas funções ao explorar o $B l o g$ por conta própria. Durante e após a oficina, a professora $\mathrm{C}$ preparou o $B \log$ elaborando mais postagens, adicionando links, imagens animadas, conhecidas como gifs; enquete, um espaço para recados, e realizou uma aula experimental cinco dias depois. Essa foi a primeira aula da escola na qual os alunos utilizaram um Blog.

Depois desta aula, a professora $\mathrm{C}$ continuou incrementando o Blog do quinto ano, mudando o plano de fundo e inserindo novas funções para que o Blog ficasse ainda mais atrativo aos alunos. A dedicação ao Blog foi tanta que ele ficou conhecido por todos da escola, ao ponto de, outras professoras a procurarem pedindo ajuda com os seus. Entre essas professoras estavam as professoras A e $\mathrm{B}$, que pediram ajuda da professora $\mathrm{C}$ para incrementar os Blog antes das aulas com o quarto ano (ver figuras 5 e 6 ).

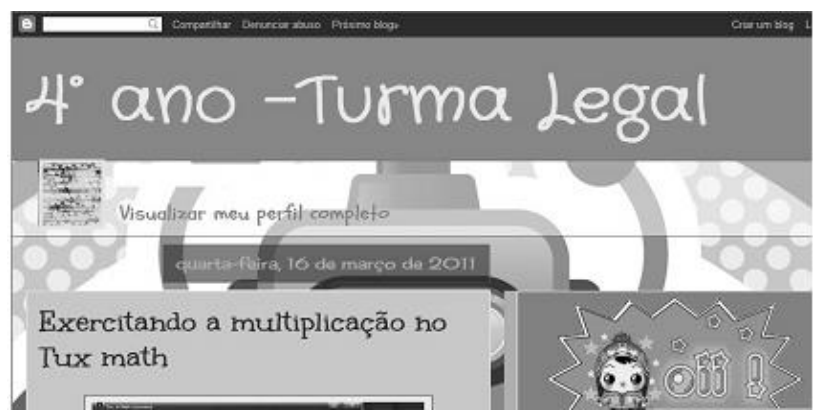

Figura 5: Blog da professora A depois das mudanças.

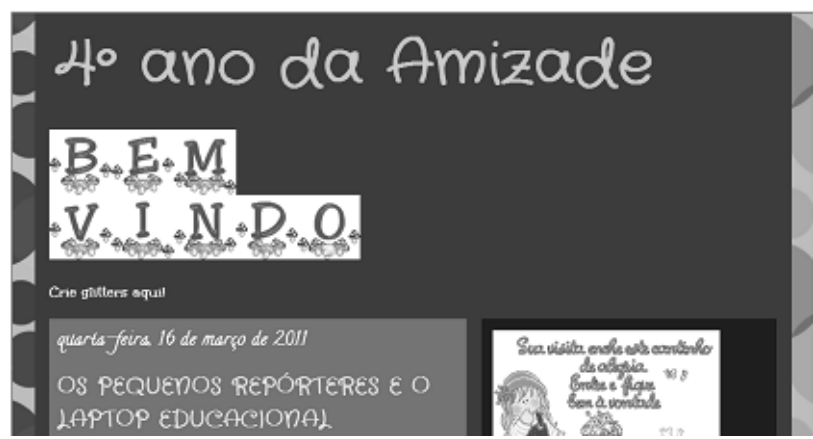

Figura 6: $B \log$ criado pela professora B depois das mudanças.

Durante o acompanhamento pedagógico, quando realizamos encontros com estas duas professoras para planejar as aulas com o Blog, ambas sugeriram uma nova proposta que contava com a participação dos alunos. Essas mudanças foram influenciadas tanto por sugestões da professora do laboratório, que aconselhou a criação de Blogs voltados para as turmas do $4^{\circ}$ ano, quanto pela aula experimental com o uso do Blog realizada pela professora $\mathrm{C}$, que aconteceu logo após a oficina.

Como comentamos anteriormente, as três professoras possuem níveis de habilidades distintos ao usar o computador. Enquanto que as professoras A e B ainda estão se apropriando não só do Blog, como do laptop, a professora $C$ já utilizava o laptop diariamente para acessar e realizar publicações no Blog. No entanto, as professoras A e B usaram, basicamente, computadores do laboratório de informática e notebooks pessoais para realizarem as produções e as publicações dos Blogs.

Durante as aulas, contudo, as duas primeiras professoras, auxiliadas por nós e pela professora do laboratório de informática, não apresentaram dificuldades para orientar os alunos sobre como acessar o Blog por meio do laptop educacional, e indicar onde eles podiam escrever os comentários, porém, tiveram dúvidas sobre como publicálos. A professora $\mathrm{C}$ não apresentou dúvidas durante aula, demonstrando segurança ao utilizar e explicar como os alunos deveriam utilizar as funções enquetes, comentários e links.

Durante a oficina, apresentamos algumas possibilidades pedagógicas do Blog, entre elas sugestões de atividades voltadas para o estímulo da escrita e leitura, já que o $B l o g$ é considerado como uma potencial ferramenta pedagógica por incentivar, particularmente, o exercício da leitura e escrita pelo aluno [30], que tem a possibilidade de expor seu texto, antes restrito ao caderno ao qual somente ele e o professor têm acesso. Essa forma de utilização da ferramenta despertou a atenção das professoras, que destacaram, exatamente, a escrita e a leitura como uma das principais dificuldades dos seus alunos do $4^{\circ}$ e $5^{\circ}$ anos.

A professora $\mathrm{C}$ manifestou que já havia acabado o conteúdo programático curricular a ser cumprido e que, após os alunos terem visto uma grande quantidade de temáticas sobre matemática para a preparação do SPAECE (Sistema Permanente de Avaliação da Educação Básica do Estado do Ceará), queria exercitar mais a escrita e a leitura e que o Blog poderia ser uma adequada ferramenta para estimular tais práticas, já que os alunos leriam e comentariam as postagens. Já as professoras A e B ainda tinham conteúdos a abordar, entre eles um texto do livro didático chamado "Como deixar seu Blog campeão de visitação", portanto, perceberam que a aula com o Blog seria uma ótima oportunidade para que soubessem o que é um Blog na prática e não somente na teoria.

Neste momento, constatamos a preocupação das três professoras tanto em trabalhar as dificuldades mais recorrentes dos alunos, como em associar o uso do Blog ao conteúdo como uma ferramenta integrada ao currículo e não como uma atividade isolada. Essa visão também é compartilhada por Grosseck, Marinho e Tárcia [16], quando afirmam que "(...) as novas tecnologias devem ser introduzidas no currículo de maneira adequada e não por uma simples eleição."

Desta forma, as três professoras realizaram aulas utilizando o Blog por meio do laptop educacional tendo em vista despertar nos alunos o interesse pela leitura e pela 
escrita, ao disponibilizarem postagens sobre atividades feitas em sala de aula e eventos acontecidos na escola e por meio da elaboração de comentários sobre estas postagens. Para isso utilizaram algumas estratégias para atrair a atenção dos alunos e envolvê-los na atividade: 1) Inseriram imagens, links, enquetes, e um novo design mais colorido do plano de fundo, 2) Publicaram postagens que abordavam atividades feitas pelos alunos e eventos ocorridos na escola.

A perfomance do laptop educacional durante as aulas foi regular, alternando momentos de rápido acesso dos Blogs e links disponíveis, visualização de vídeos, participação em enquetes e postagem de comentários pelos alunos com momentos de lentidão devido ao grande número de pessoas acessando simultaneamente a Internet, o que diminuiu a velocidade da conexão da rede wireless.

Ao final das aulas, realizamos entrevistas com as professoras objetivando identificar o que o uso do Blog agregou aos alunos e se o objetivo proposto para a aula foi atingido. A professora $\mathrm{C}$ destacou a leitura e a escrita com uma das principais vantagens do uso da ferramenta.

A questão da escrita e da leitura foi assim algo que a gente mais conseguiu atingir, a gente pode ver alguns erros de ortografia e de concordância que eles mais cometem para eles mesmo se corrigirem ou até mesmo a gente imprimir uma página para a gente corrigir em grupo, ver os erros mais comuns e ir lá no Blog de novo e consertar (Entrevista, 10/02/2011).

$\mathrm{Na}$ fala da professora $\mathrm{C}$ percebemos a preocupação com a escrita correta dos alunos. Deparando-se com os erros apresentados pelos alunos durante a escrita dos comentários, a professora $\mathrm{C}$ pediu que eles escrevessem o texto antes em um papel ou a mostrassem no laptop para que ela pudesse corrigi-lo antes de ser publicado.

A professora A também concordou com a ideia de que a escrita do Blog deve ser mais formal, já que estará disponível podendo ser vista por muitas pessoas, e acrescentou que eles terão quer ler para conseguir comentar algo coerente a cada postagem. "Para eles puderem participar eles vão ter que ler, então, está desenvolvendo a leitura e também a criatividade, e também a parte de escrita" (Entrevista, 18/03/2011).

Corroborando a opinião da professora $\mathrm{A}$, a professora $\mathrm{B}$ comentou que a indispensabilidade da leitura acabaria despertando nos alunos uma consciência sobre o conteúdo e a qualidade dos comentários. "Acho que realmente favorece a aprendizagem porque eles vão ter que ler, ver o que eles estão escrevendo e ter a consciência que eles não podem escrever tudo nem de qualquer jeito" (Entrevista, 18/03/2011).

A questão da escrita também acabou gerando uma situação inusitada: durante a aula do $5^{\circ}$ ano da manhã, um aluno começou a rir de um colega ao ler seu comentário e identificar a palavra "legal" terminada com a vogal "u". Ao perceber a situação, a professora $\mathrm{C}$ usou o erro para incentivar que o aluno ajudasse o que havia escrito a palavra de forma errada.

Desta forma, ao mesmo tempo em que ela estimulou a cidadania entre os alunos, também percebeu que pela primeira vez eles estavam tendo a oportunidade de ler o texto uns dos outros, realizando correções nos textos dos colegas: "Eles vendo os erros uns dos outros eu achei isso também muito legal, "ah colocaram o legal sem o 1, colocaram o legal com u" e o outro escuta e já sabe que não é com u é com 1, é diferente de você estar corrigindo. Quando você corrige ele olha a nota ele não vai olhar o que errou" (Entrevista, 10/02/2011).

Essa situação comprova a força da inteligência coletiva do ciberespaço, em que quanto mais as informações são compartilhadas "mais inteligente e politicamente consciente uma sociedade deve ficar" [23]. Ou seja, ao compartilharmos nossas produções, fornecemos informações e também podemos receber sugestões e críticas.

$\mathrm{O}$ incentivo à participação também foi demonstrado pela postura das professoras em sala de aula ao estimularem, a todo o momento, a produção dos alunos, de divesas formas.

A professora $\mathrm{C}$ percebeu que os alunos estavam lendo os textos, mas não sabiam ao certo o que deveriam comentar em cada postagem e, portanto, limitavam-se a escrever mensagens para a professora ou simplesmente manifestavam que haviam achado o texto "legal" ou "bom". Para estimular a escrita, a professora começou a sugerir algumas temáticas que poderiam ser abordadas em cada postagem. Por exemplo: na postagem sobre o filme "RRRrrrr!!! Na idade da pedra" ela orientou que eles comentassem qual parte gostaram mais, o que acharam engraçado e que sugerissem outros filmes.

As professoras A e B apenas solicitaram que os alunos lessem e comentassem as postagens, mas não orientaram quais temas deveriam ser enfocados, o que gerou comentários menos aprofundados. Observamos que a postura destas professoras reflete o estágio inicial de apropriação tecnológica. Elas não conseguiram perceber essa dificuldade dos alunos, pois estavam concentradas em fazê-los ler as postagens e escreverem algo nos comentários. Já a professora $\mathrm{C}$ conseguiu ver além do uso inicial da ferramenta, propondo novas formas de interação por meio do enfoque em subtemas acerca dos temas centrais das postagens. Dessa forma, percebemos que a mediação pedagógica do professor é imprescindível para o uso da tecnologia na educação, principalmente, quando se trata de recursos em que o aluno encontra-se na posição de autor.

A mediação da professora $\mathrm{C}$ se mostrou fundamental quando estimulou que os alunos comentassem as posta- 
gens uns dos outros, configurando a proposta de colaboração oferecida pelo Blog. Segundo Gomez [15], a colaboração acontece quando os alunos são estimulados a convergir suas postagens para um mesmo local, construindo seus conhecimentos em torno de um tema. A professora C destacou a colaboração possibilitada pelo Blog com um dos aspectos que mais the chamou atenção durante a aula: (...) talvez se a atividade fosse no livro ou no caderno eles não estariam tão envolvidos como eles estavam, onde é que a gente viu um querendo comentar da tarefa do outro? "ah, o quê que tu colocou na questão tal" "ah, que legal, na minha questão tem isso", não tem, cada um faz o seu, o mais rápido que pode para terminar (Entrevista, 10/02/2011).

Outro momento de colaboração aconteceu quando a professora A foi auxiliar uma aluna a publicar um comentário, mas não conseguiu e pediu ajuda a uma segunda aluna. Percebemos por esta ação que a docente observou que podia aprender mais sobre a ferramenta interagindo e colaborando com os próprios alunos. Valente [34] comenta que fazer parcerias com os alunos, pedindo ajuda no que os jovens conhecem mais, é a postura que o professor deve ter ao usar as tecnologias para a Educação.

Nas aulas do Blog cada aluno teve autonomia para escrever comentários sobre qualquer uma das postagens expostas na ferramenta e também possuía acesso aos comentários dos outros colegas. O bom uso dessa autonomia proporcionada pelo recurso impressionou a professora C: "Eles tinham autonomia, ninguém copiou o comentário de ninguém, na tarefa você vê que um copia a tarefa do outro" (Entrevista, 10/02/2011).

Essa fala demonstra que quando somente a professora lê e corrige a "tarefa", os alunos não se importam em copiar a resposta uns dos outros, mas quando a "tarefa" está exposta para todos na Internet e tem como principal identificação o nome de quem a fez, o interesse e a responsabilidade do autor aumenta.

Quanto às desvantagens no uso do Blog em sala de aula, a professora B comenta que os obstáculos encontrados não estão relacionados com a ferramenta em si, mas com a falta de apropriação do recurso. "O meu problema é porque a gente ainda tá se apropriando do recurso, se apropriando desse tipo de recurso na sala de aula, a dificuldade que eu tenho ainda é essa, que eu ainda não tenho essa habilidade nesse tipo de recurso" (Entrevista, 18/03/2011). No entanto, ela complementa seu relato dizendo que quanto mais segurança tiver em usar a ferramenta, melhor poderá empregá-la com os alunos.

Percebemos pela fala da professora B que ela possui interesse em continuar usando o $B \log$, mas que para isso precisará passar por novos momentos de apropriação tecnológica. Daí, constatamos a necessidade de formações contínuas que estimulem esses usos. A professora também recomenda que no próximo ano letivo o Blog seja utilizado desde o começo das aulas para que no de- correr do semestre tanto ela quanto os alunos possam estar mais familiarizados com a ferramenta.

Para a professora $\mathrm{C}$, não há desvantagens em usar a ferramenta em sala de aula, "a não ser que eles comecem a comentar entre eles mesmos e aparece algum comentário que não seja de acordo com o que a gente está esperando" (Entrevista, 11/02/2011). Porém, ela afirmou que até o momento isso não aconteceu.

Nas entrevistas realizadas ao final das aulas, também visamos identificar as percepções das professoras acerca dos avanços nas habilidades de uso do Blog. A professora $\mathrm{C}$ disse que percebeu sua melhora, mas que ainda tem muito que aprender. "Eu não estou dominando $100 \%$, mas a gente vai descobrindo aos pouquinhos." (Entrevista, 10/02/2011). O depoimento exposto acima não traduz os grandes avanços instrumentais e pedagógicos que esta professora conquistou desde a Oficina. Antes deste momento, ela nunca havia criado um Blog ou utilizando-o na função de "proprietária". No dia da aula, ela presenteou os alunos com um novo espaço de aprendizagem com vários atrativos tanto em relação ao visual quanto às opções de interação disponibilizadas.

A percepção da professora A retrata avanços na utilização do Blog como ferramenta pedagógica em sala de aula. "Eu estou mais tranquila, acho que se não tiver ninguém comigo eu já consigo dar uma aula usando a ferramenta [o Blog]" (Entrevista, 18/03/2011).

Mas, mesmo considerando o relato da professora A e testemunhando seu avanço percebemos que os passos dados no uso do Blog ainda são iniciais e que para uma maior evolução na habilidade com esta e outras ferramentas da Web 2.0, outras formações serão necessárias e essenciais para a continuidade das aulas com estes recursos. Esta constatação está alinhada com a percepção da docente $\mathrm{B}$, relatada anteriormente, quando reconhece que ainda está em processo de apropriação do Blog e que esse fato ainda representa um obstáculo para o seu uso em sala de aula, embora reconheça que a prática lhe trará a segurança que falta.

Os indícios de avanços das professoras no domínio instrumental e pedagógico do Blog, acompanhados por nós durante a duração desta pesquisa, demonstram que não somente é possível que as professoras se apropriem como utilizem a ferramenta Blog juntos aos alunos. Consideramos, no entanto, que mais importante do que as indicações de melhora no domínio instrumental estão o envolvimento e o interesse em aprender a utilizar a tecnologia como recurso de ensino e aprendizagem.

\subsection{Follow-up: o uso e o não-uso do Blog pelos docentes}

Após as primeiras aulas, as professoras A e B continuaram a utilizar o Blog durante o ano de 2011. Porém, ambas as professoras passaram a atuar em outros anos de 
ensino, respectivamente, no $3^{\circ}$ e no $1^{\circ}$ anos, o que dificultou o uso do $B \log$, dado que ele havia sido pensado para os alunos do $4^{\circ}$ ano.

No entanto, ambas as professoras pensam em retomar o uso da ferramenta com suas atuais turmas, de acordo com as especifidades dos alunos. "O Blog está parado, mas estou com vontade de retomá-lo com outro nome, agora voltado para os alunos do $3^{\circ}$ ano. " (Entrevista, 11/07/2013), afirmou a professora A, que pretende continuar realizando atividades que incentivem a escrita dos alunos.

Atuando com estudantes que ainda serão alfabetizados, a professora B pensa em utilizar o Blog para divulgar juntos aos pais dos alunos os trabalhos feitos em sala de aula.

A professora C usou o Blog também em 2012, no entanto, substituiu o recurso por outro também provindo da Web 2.0, o Facebook. A docente alegou que a baixa velocidade na conexão da Internet wireless também dificultou o uso do Blog em sala. "Não usei mais [o Blog] dentro de sala. A conexão da Internet na escola está um caso sério. Os alunos estão muito ligados ao Facebook, já que Maomé não vai à montanha, eu fui até eles através do Face" (Entrevista, 18/07/2013).

Ainda segundo ela, a atualização e uso do Blog pelo laptop é mais complicado, pois a tela pequena não mostra a configuração completa da ferramenta. Já o Facebook é mais fácil e rápido de atualizar pelo laptop.

Para o uso da rede social em sala, a professora criou uma grupo no qual compartilha informações com os alunos. "Criei um grupo fechado no Face onde a gente compartilha tudo. A agenda do dia é postada para quem não pôde estar presente, dou dicas de filmes para feriados, compartilhamos fotos da turma, projetos, dicas de gibis, livros e falamos de assuntos do momento". (Entrevista, 18/07/2013).

Segundo ela, os alunos também podem realizar publicações, mas as mesmas só aparecem no grupo depois de sua autorização. "É para evitar postagens indevidas. Falamos sobre isso na aula também." (Entrevista, 18/07/2013).

Os planos futuros da professora para o uso do Facebook incluem a entrada dos pais no grupo criado. "Estou trazendo as mães também para o grupo para que elas possam confiar no conteúdo e permitir que eles [alunos] façam e também para que acompanhem a conta dos alunos e e possam participar também com dicas, tirar dúvidas, avisar quando o filho não puder ir à escola, contribuir de alguma forma. Muitas trabalham fora, é uma forma de acompanhar". (Entrevista, 18/07/2013).

Mesmo usando atualmente o Facebook ao invés do $B \log$, a professora $\mathrm{C}$ afirma que a experiência com esta última ferramenta contribuiu com sua prática pedagógica e com o aprendizado dos estudantes. "Eles [os alunos] foram construtores de várias postagens do Blog. Isso deu um impulso para que pudessem também participar mais nas aulas. Através de posts, muitas discussões foram geradas em sala." (Entrevista, 18/07/2013).

Segundo as professoras A e B, o uso do Blog em sala de aula ocasionou, principalmente, a melhora na escrita e ampliação da comunicação entre alunos e docentes. "Com o Blog os alunos tem mais comunicação com a gente [professores]. Na hora que eles escrevem a gente já vê que eles estão melhorando na escrita, na maneira de falar, dá para a gente ver o progresso dos alunos" (Professora A, Entrevista, 11/07/2013). Já a professora B comenta que a escrita foi estimulada pela realização dos comentários sobre as postagens. "Foi um novo aprendizado, eu trabalhei com os meninos que também utilizaram fazendo comentários. Foi bem produtivo". (Professora B, Entrevista, 11/07/2013).

Quanto à apropriação instrumental da ferramenta, as professoras A e B afirmam que precisaram de ajuda mais do que auxiliaram outros professores da escola. "As outras professoras foram além do que eu fui no uso do Blog, como a professora da biblioteca, por exemplo." (Professora A - Entrevista, 11/07/2013).

A professora B comenta que teve ajuda principalmente da professora C. "Eu que ia mais atrás de ajuda porque eu tinha mais dificuldade e ia pedir ajuda para a professora $\mathrm{C}$ e para a professora do laboratório para colocar imagens e gifts no Blog e nas postagens". (Entrevista, 11/07/2013).

Após a oficina e a realização das aulas, conforme citamos anteriormente, a professora $\mathrm{C}$ foi requisitada pelas outras docentes para auxiliar na construção dos Blog. Segundo ela quase todas professoras da escolas solicitaram algum tipo de auxílio. "Alguns [Blogs] foram feitos $100 \%$ por mim outros só contribui com alguns detalhes" (Entrevista, 18/07/2013).

A professora $\mathrm{C}$ também ressalta que uma apropriação multiplicadora também aconteceu entre os alunos do $5^{\circ}$ ano que começaram a utilizar o Blog da turma dentro e fora de sala de aula e até criaram seus próprios Blog. "Tive alunos que criaram Blog. Eles pediram informação sobre templates, como colocar gifs, trocar a fonte e a cor de textos. Eles usavam como diário virtual." (Entrevista, 18/07/2013).

Devido as dificuldades de uso das próprias professoras, os alunos das docentes A e B não se manifestaram para criar Blog próprios.

A partir desse follow-up, verificamos que, além das dificuldades instrumentais, as mudanças das professoras para outros anos de ensino, assim como as limitações do laptop educacional e a baixa velocidade da conexão de Internet acabaram prejudicando e desestimulando as docentes no uso do Blog.

No entanto, os avanços e ganhos no uso pedagógico, 
descritos anteriormente, nos apontam a importância de estimular os professores a continuarem experienciando o uso desta e de outras ferramentas da $W e b 2.0$, seja por meio de formações que oportunizem novos momentos de apropriação tecnológica para que as professoras avancem no uso instrumental, ou mesmo pelo estímulo da apropriação multiplicadora que acontece entre os professores e os alunos.

\section{Considerações finais}

O uso da Web 2.0 na educação, mais especificamente da ferramenta $B l o g$, tem sido objeto de várias pesquisas como vimos anteriormente $(13 ; 14 ; 33)$. No entanto, o seu efetivo uso como recurso de ensino e aprendizagem no âmbito escolar depende de alguns fatores que foram identificados durante esta investigação.

Primeiramente, constatamos que as professoras conheciam o Blog, mas não o utilizavam como ferramenta pedagógica. Desta forma, a realização da oficina permitiu uma apropriação tecnológica e das potencialidades educativas desta ferramenta. Portanto, se mostrou como uma adequada escolha para instigar a elaboração de propostas de incorporação do Blog em sala de aula.

Os resultados indicam que as três professoras obtiveram avanços no uso instrumental e pedagógico do Blog. Esses avanços, no entanto, ocorreram de forma heterogênea, estando principalmente relacionados ao domínio instrumental prévio do computador. Outras pesquisas [8; 27] corroboram os dados encontrados, ao relatarem a falta de habilidade e conhecimento dos professores no uso do computador como um obstáculo para a aprendizagem em informática educativa.

Quanto à forma de utilização pedagógica do Blog, constatamos que as professoras desejam principalmente que haja a participação dos alunos, identificando-os como personagens ativos.

No follow-up realizado, as professoras reconhecem o potencial de ferramentas da Web 2.0 para promover uma maior motição dos estudantes para o aprendizado. Apesar de termos verificado que duas professoras não deram continuidade, as mesmas constataram que estas ferramentas podem ser utilizadas como auxílio pedagógico em sala de aula. Por outro lado, pela entrevista realizada com a professora $\mathrm{C}$, observamos que a oficina proporcionou uma motivação e que ela foi além do $B l o g$, tendo entendido que as ferramentas da $W e b 2.0$ podem ser usadas como uma forma de atingir os alunos e motivá-los a aprender. Seja esse alcance por meio do Blog, Facebook, ou outra ferramenta da $W e b 2.0$, constatamos que o fundamental é traçar um caminho para chegar no interesse dos alunos e permitir que eles se expressem de variadas formas.

As demandas da sociedade atual exigem que os docentes possuam habilidades tecnológicas, no entanto, para que eles possam se apropriar e usar essas tecnologias no cotidiano escolar, os mesmos precisam de condições adequadas. Daí, constatamos a importância de projetos como o UCA que, mesmo com as fragilidades já relatadas em relação ao laptop e à conexão da Internet, proporcionam infra-estrutura paras as escolas e também reconhecem a necessidade de formações docentes para o uso pedagógico da tecnologia, como o Blog. Durante estes momentos tão primordiais, os professores têm orientação e tempo tanto para se apropriar melhor destes recursos quanto para pensar em possibilidades de usos pedagógicos.

Pesquisas futuras podem realizar um estudo comparativo entre escolas contempladas com o Projeto UCA, observando diferenças na utilização de ferramentas da Web 2.0 por professores da Educação Básica. Consideramos, contudo, que o final desse trabalho é apenas o início para novas caminhadas e descobertas que se configuram como os primeiros passos bem-sucedidos de uma longa caminhada para que a filosofia da Web 2.0 seja vivenciada por professores e alunos.

\section{Referências}

[1] M. E. Almeida. Proinfo: Informática e Formação de Professores MEC/SEED, Brasília, Séries de Estudos à Distância, 2000.

[2] E, Barbosa; A, Granado. WeBlog, Diário de Bordo. Porto Editora, Porto, 2004.

[3] R. C. Bogdan; S. K. Biklen. Investigação Qualitativa em Educação: uma introdução à teoria e aos métodos. Portugal: Porto Editora. 1994.

[4] Brasil. Princípios orientadores para o uso pedagógico do laptop na educação escolar. Brasília, 2008.

[5] B. B. T. Carmo; R. L. J. Pontes. Collaborative learning concept implementation through Web.2.0 tools: the case of industrial engineering fundamentals' discipline. International Journal of Engineering Education, v. 29: 205-214, 2013.

[6] A. Chizzotti. Pesquisa qualitativa em ciências humanas e sociais. Vozes, São Paulo, 2006.

[7] P. G. Cysneiros. Novas Tecnologias no Cotidiano da Escola. Curso ministrado na $23^{a}$ Reunião Anual da ANPED - Associação Nacional de Pós Graduação e Pesquisa em Educação. Caxambu, MG, 2000.

[8] N. L. R. Fernandes. Professores e computadores: 
navegar é preciso. Mediação, Porto Alegre, 2004.

[9] U. Flick. Uma introdução à pesquisa qualitativa. $3^{\circ}$ ed. Bookman, Porto Alegre, 2009.

[10]

V. Fonseca; C. Lindemann. Webjornalismo participativo: repensando algumas questões técnicas e teóricas. Revista Famecos. 1(34): páginas 86-94,

[11] 2007.

P. Freire. Pedagogia da Autonomia: saberes necessários à prática educativa. Paz e Terra, São Paulo, 1996.

[12] A.C. Gil. Métodos e técnicas de pesquisa social. 3 ed. Atlas, São Paulo,1991.

[13] M. J. Gomes. Blogs: um recurso e uma estratégia pedagógica. In Actas do VII Simpósio Internacional de Informática Educativa. Leiria, páginas 311-315, 2005.

[14] M. J. Gomes; A. M. Lopes. Blogues escolares: quando como e porquê. In Actas do Encontro WeBlog na Educação: 3 experiências, três teste-

[15] munhos. Setúbal, páginas 117-133, 2007.

M. V. Gomez. Cibercultura, formação e atuação docente em rede. Líber Livro, Brasília, 2010.

[16] G. Grosseck.; S.P. Marinho; L.Tárcia. Educação a distância baseada na Web 2.0: a emergência de uma Pedagogia 2.0. Revista Educação e Linguagem, Vol. 12, n19. 2009.

[17] D. Guedes; J. A. Castro Filho. A seleção de objetos educacionais digitais por professores. In Simpósio Brasileiro de Informática na Educação, João Pessoa, Paraíba. 2010.

[18] S. Gutierrez. WeBlog e educação: contribuição para a construção de uma teoria. Revista Novas Tecnologias na Educação - Renote. Porto Alegre, CINTED-UFRGS, 3(1), s/p, $2005 . \quad$ Disponível em: <http://www.cinted.ufrgs.br/renote/maio2005/arti gos/a15_welogs.pdf>. Data de acesso em: 26 jul. 2012.

[19] L. Harasim et al. Redes de aprendizagem: um guia para ensino e aprendizagem on line. Senac, São Paulo, 2005.

[20] S. Hemmi; R. Bayne; Landt. The appropriation and repurposing of social technologies in higher education. Journal of Computer Assisted Learning 25 (1), p. 19-30, 2009.

[21] S. Isotani et al. Estado da Arte em Web Semântica e Web 2.0: Potencialidades e Tendênciasda Nova Geração de Ambientes de Ensino na Internet. Revista Brasileira de Informática na Educação. 17(1): páginas 30-42, 2009.

[22] H. N. Kim. The phenomenon of Blog and theoretical model of Blog use in educational contexts. Journal Computers \& Education. 51(3), p.13421352, 2008.

[23] A. Lemos; P. Lévy. O futuro da Internet: em direção a uma ciberdemocracia planetária. Paulus, São Paulo, 2010.

[24] M. Ludke; M. E. D. André. Pesquisa em Educação: abordagens qualitativas. Ed. Pedagógica e Universitária, São Paulo, 1986.

[25] S. P. Marinho et al. Oportunidades e possibilidades para a inserção de interfaces da Web 2.0 no currículo da escola em tempos de convergências de mídia. Revista e-Curriculum. 4(2), s/p, 2009. Disponível

[26] http://www.pucsp.com.br/ecurriculum

Data de acesso em: 20/02/2011.

M. Mendes. Introdução ao Laptop Educacional em Sala de Aula: Indícios de Mudanças na Organização e Gestão da Aula. Dissertação de Mestrado em Educação. Pontifícia Universidade Católica de São Paulo (PUC/SP), São Paulo, 2008.

[27] S. R. Moreira. Análise de reações de professores face à Introdução do Computador na Educação: o caso do Projeto UCA - Um Computador por Aluno no Colégio Estadual Dom Alano Marie Du' Noday (TO). Dissertação de Mestrado em Educação, Universidade de Brasília (UNB), Brasília, 2010.

[28] S.F.S. Moresco; P.A. Behar. Blog para a aprendizagem de Física e Química. RENOTE - Revista Novas Tecnologias na Educação. 4(1), on-line, 2006. Disponível em:

<http://www.cinted.ufrgs.br/

renote/jul2006/artigosrenote/a44_21233. pdf>. Data de acesso em jun. 2010.

[29] R. M. C. Oliveira. Interfaces colaborativas e Edu- 
cação: o uso do Blog como potencializador do processo de avaliação. In Ambientes educativos emergentes. Braga, Universidade do Minho, páginas 101-118, 2008.

[30] A. F. T. Primo; R. C. Recuero. Hipertexto Cooperativo: Uma Análise da Escrita Coletiva a partir dos Blog e da Wikipédia. Revista da FAMECOS. n23: 54-63, 2003.

[31] W. Richardson. Blog, Wikis, Podcast and other powerful Web tools for classrooms. Corwin Press, Thousand Oaks, CA, 2006.

[32] M. B. F. Santos; M. K. Borges. Considerações sobre o Projeto UCA e o currículo escolar. In Anais II Seminário Web-Currículo - Integração de Tecnologias de Informação e Comunicação ao Currículo, São Paulo, páginas 2446-2458, 2010.

[33] L.T. Silva; M. Albuquerque. Blog pedagógicos: possibilidades de interação por meio da escrita coletiva de hipertextos cooperativos. Revista Latinoamericana de Tecnología Educativa RELATEC, VOLUME, NÚMERO, PÁGINAS, 2009. Disponível em: http://campusvirtual.unex.es/cala/editio/ Data de acesso em: 26 jul. 2012.

[34] J. A. Valente. Um Laptop Para Cada Aluno: promessas e resultados educacionais efetivos. In: Almeida, M.E.B.; Prado, M.E.B.B. (org.) O Computador Portátil na Escola: mudanças e desafios nos processos de ensino e aprendizagem. Avercamp, São Paulo, 2011.

[35] V. Venâncio et al. Um computador por Aluno: um relato dos protagonistas do Piloto de São Paulo. In XIX Simpósio Brasileiro de Informática na Educação (SBIE), Workshop IV: Projeto Um Computador por Aluno (UCA) \pm Brasil: panorama, avaliação e perspectivas, Fortaleza (CE), s/p, 2008. 